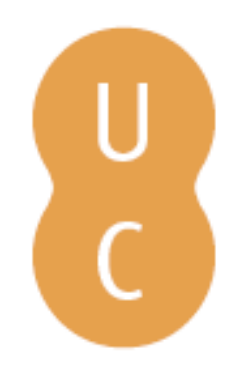

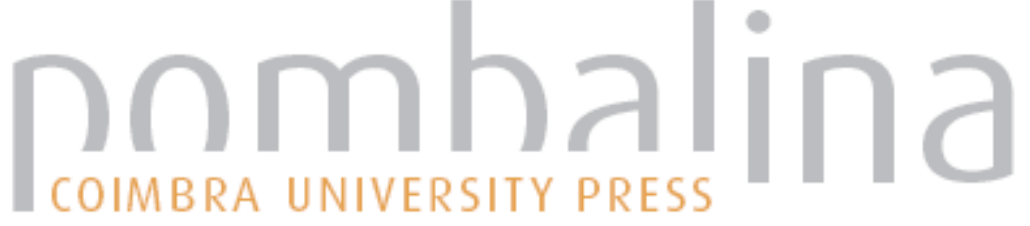

\section{Sobre a geometria fractal}
Autor(es):
Oliveira, Paula de
Publicado por: Imprensa da Universidade de Coimbra; Gradiva
URL persistente:
URI:http://hdl.handle.net/10316.2/32660
DOI:
DOI:http://dx.doi.org/10.14195/978-989-26-0389-6_6

Accessed : $\quad$ 26-Apr-2023 16:14:23

A navegação consulta e descarregamento dos títulos inseridos nas Bibliotecas Digitais UC Digitalis, UC Pombalina e UC Impactum, pressupõem a aceitação plena e sem reservas dos Termos e Condições de Uso destas Bibliotecas Digitais, disponíveis em https://digitalis.uc.pt/pt-pt/termos.

Conforme exposto nos referidos Termos e Condições de Uso, o descarregamento de títulos de acesso restrito requer uma licença válida de autorização devendo o utilizador aceder ao(s) documento(s) a partir de um endereço de IP da instituição detentora da supramencionada licença.

Ao utilizador é apenas permitido o descarregamento para uso pessoal, pelo que o emprego do(s) título(s) descarregado(s) para outro fim, designadamente comercial, carece de autorização do respetivo autor ou editor da obra.

Na medida em que todas as obras da UC Digitalis se encontram protegidas pelo Código do Direito de Autor e Direitos Conexos e demais legislação aplicável, toda a cópia, parcial ou total, deste documento, nos casos em que é legalmente admitida, deverá conter ou fazer-se acompanhar por este aviso.

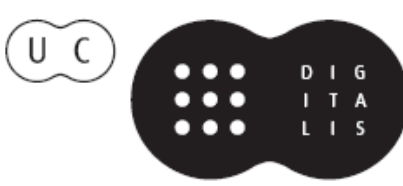


C I E N C I A I B E R T A

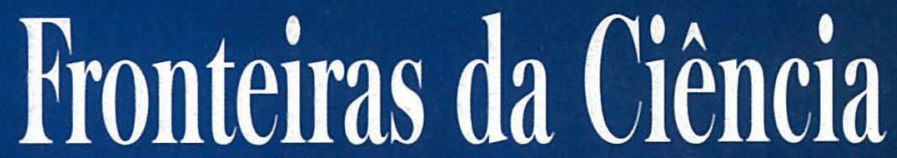

Desenvolvimentos Recentes - Desafios Futuros

RUI FAUSTO • CARLOS FIOLHAIS • JOÃO FILPE QUURRÓ

Coordenadores

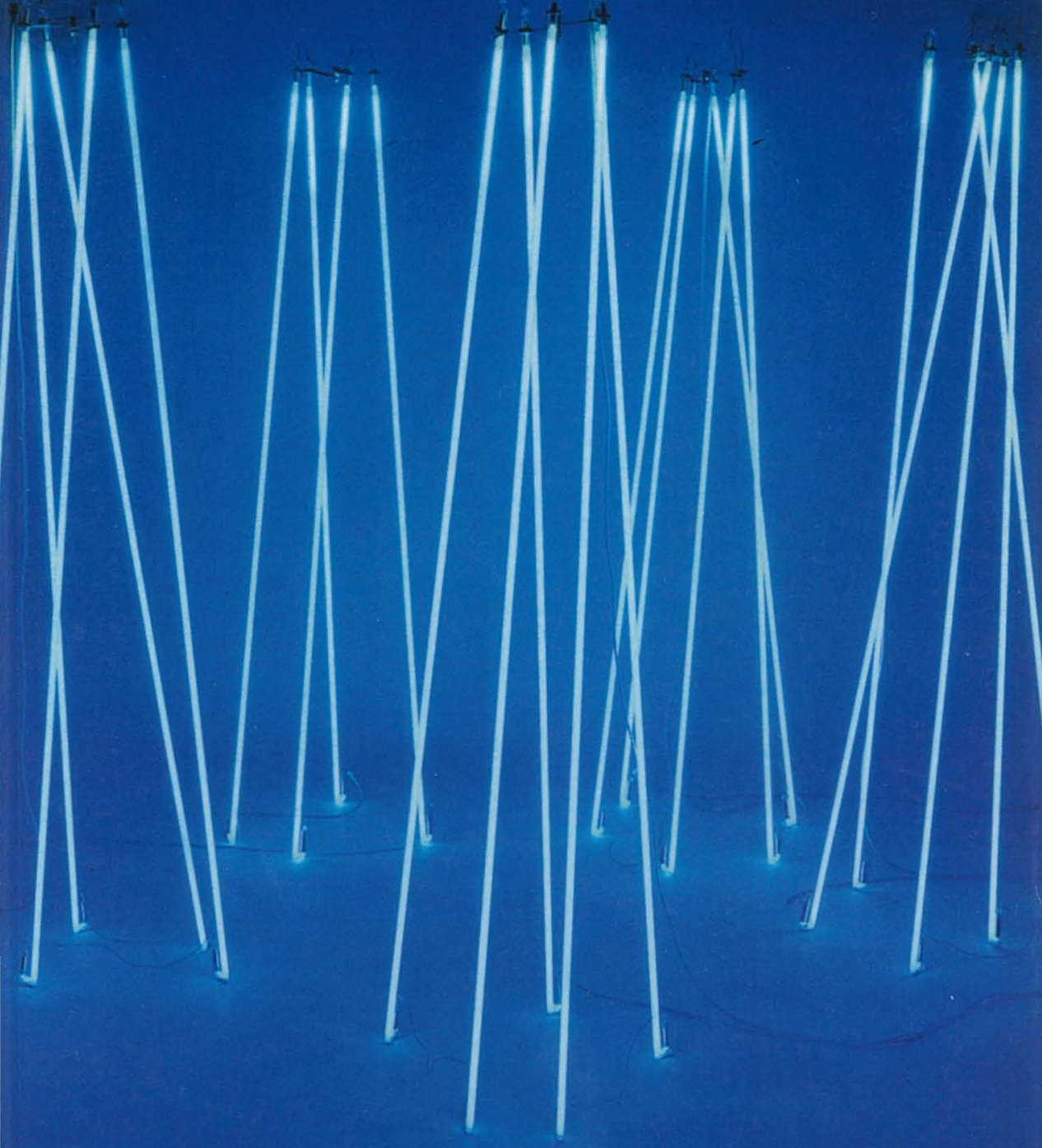

gradiva - Imprensa da Universidade de Coimbra 
(Página deixada propositadamente em branco) 


\section{RUI FAUSTO, CARLOS FIOLHAIS JOÃO FILIPE QUEIRÓ \\ Coordenadores}
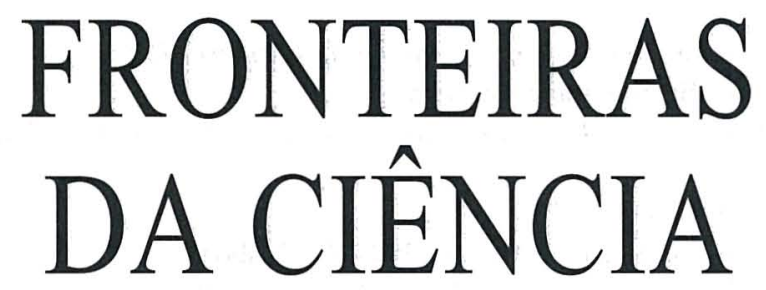

Desenvolvimentos Recentes Desafios Futuros 
(C) Gradiva - Publicações, L. da / Imprensa da Universidade de Coimbra, 2003 Coordenação editorial: Rui Fausto, Carlos Fiolhais e João Filipe Queiró Tradução: Jean Burrows, Vivien Burrows, Rui Fausto, Carlos Fiolhais e João Filipe Queiró

Revisão do texto: Isabel Pedrome

Capa: António Barros [Imprensa da Universidade. Coimbra], sobre imagem de «Águas Vivas», escultura de Silvestre Pestana, 2001

Foto: António Alves; Infografia: ESTÍMULUS [design]; Cortesia: Galeria Alvarez-Arte Contemporânea

Paginação: António Resende e Paula Isabel Jorge

Impressão e acabamento: G.C. - Gráfica de Coimbra, L. ${ }^{d a}$

Reservados os direitos para Portugal por:

Gradiva - Publicações, L. ${ }^{\text {da }}$ e Imprensa da Universidade de Coimbra

Gradiva - Publicações, L.da

Rua Almeida e Sousa, 21, r/c, esq.•1399-041 Lisboa

Telefs. $213974067 / 8 \cdot 213971357 \cdot 213953470$

Fax $213953471 \cdot$ Email: gradiva@ip.pt

URL: http://www.gradiva.pt

Imprensa da Universidade de Coimbra

Rua Antero de Quental, 195 • 3000-033 Coimbra

Telefs. 351239853110

Fax 3512398531 19・e-mail: fjrpress@ci.uc.pt

URL: http://www.imp.uc.pt

ISBN: 972-662-923-3

1." edição: Agosto de 2003

Depósito legal n. ${ }^{\circ} 199$ 463/2003 
Paula de Oliveira

Departamento de Matemática

Faculdade de Ciências e Tecnologia

Universidade de Coimbra

\section{Sobre a geometria fractal}

$\mathrm{Na}$ vasta literatura fractal de que hoje dispomos, e onde se distinguem as inúmeras publicações de Benoît Mandelbrot, são-nos apresentadas fabulosas visões e elaboradas teorias de geometria fractal. Após uma reflexão sobre elas, o olhar em torno adquire maior acuidade, mostrando-nos inúmeros objectos naturais, de geometria irregular, mas que possuem o mesmo grau de irregularidade em todas as escalas. Esta propriedade, designada por auto-semelhança ou invariância de escala, permite-nos conhecer a estrutura do todo pela ampliação de uma parte.

A geometria fractal surge assim como um instrumento particularmente adequado à descrição de padrões irregulares e fragmentados como, por exemplo, os vasos sanguíneos, os pulmões, as árvores, as montanhas, as zonas costeiras, as nuvens ou mesmo as galáxias. O essencial nesta nova descrição do real é que potencia, de certo modo, a visão, reeducando o olhar, que atinge o cérebro de modo mais rápido que qualquer outra aproximação sensorial. De facto, com o olhar adquirimos a informação de modo global e não sequencial, seguindo uma sucessão temporal. A geometria fractal, fornecendo uma tão completa descrição dos objectos e possuindo toda a informação de modo compactado, surge assim como uma geometria particularmente adequada à construção (ou à desconstrução) do universo.

Um segundo aspecto da geometria fractal que parece essencial é constituir um instrumento que, mais do que descritivo, é explicativo, pois, baseando-se na ideia de auto-semelhança, fornece um kit para construir o objecto global. Este aspecto contribuiu de certo modo para alterar a visão 
clássica da ciência no que toca ao princípio da causalidade, no contexto do qual as causas e os efeitos são classificados do simples ao complexo, considerando-se que as causas simples produzem efeitos simples e as causas complexas produzem efeitos complexos. Esta visão linear da causalidade é de certo modo contrariada pela geometria fractal, que, mostrando que a simplicidade da fórmula fractal pode gerar complexidade, sugere que causas simples podem provocar comportamentos de grande complexidade.

Os argumentos anteriores não explicam, no entanto, a razão pela qual a geometria fractal produziu um impacto tão grande na ciência e na arte. Uma primeira resposta poderia basear-se no facto de as geometrias dominantes sempre terem protagonizado uma grande influência na ciência e na arte. De facto, durante 2000 anos a nossa visão do mundo foi modelada por linhas, triângulos e polígonos regulares. Era o domínio da geometria euclidiana, que constituiu uma poderosa abstracção do mundo real e inspirou, sem dúvida, a filosofia da harmonia de Platão e permitiu uma explicação do movimento dos planetas, do comportamento das marés e do fluir das ondas. A geometria euclidiana fundamentou ainda a perspectiva na pintura e porventura o fluxo temporal linear na descrição literária. Desenvolveu o gosto pela simplicidade e por um certo minimalismo. Mas, neste contexto, não era possível explicar a complexidade de certos fenómenos, como por exemplo as turbulências atmosférica e oceânica. Surge então, mais tarde, a geometria de Riemann, que, com o seu conceito de espaço curvo, forneceu ainda um contexto particularmente adequado ao desenvolvimento da teoria da relatividade geral. Parece plausível que esta geometria tenha inspirado certas correntes de pintura moderna, a arquitectura orgânica e possivelmente um fluxo temporal não linear presente em algumas formas literárias. No entanto, como instrumento descritivo do mundo real não se adaptava, claramente, a conceitos como enrugado, granuloso, poroso, ramificado ou oscilatório. E é então que surge a geometria fractal, que se adapta de modo perfeito à descrição de tais conceitos.

No entanto, a questão permanece: porque pode a geometria fractal assumir um papel central na nossa visão do universo? Porque constitui a linguagem natural dos fenómenos caóticos que surgem na evolução de certas populações, em determinados comportamentos fisiológicos, na turbulência, na meteorologia? Porque produz imagens surpreendentemente belas? Responderíamos que, porventura, por todas as razões anteriores, mas sobretudo porque o conceito de fractal toca de certo modo as fronteiras do conhecimento. De facto, na construção de fractais determinísticos utiliza-se um processo dinâmico. O processo inicia-se com uma lei simples 
e as iterações produzem uma complexidade crescente. Consideremos, por exemplo, o conjunto de Mandelbrot, nos seus múltiplos aspectos. Ele pode ser construído, tal como os outros fractais, a partir de alguns bits de informação. Um programa curto e simples pode produzi-lo. Mas uma eternidade não chegaria para o visitar. Uma catalogação das diferentes imagens do seu interior exigiria uma quantidade menor de informação. E, se uma eternidade não é suficiente para visitar o conjunto de Mandelbrot, ele próprio é uma representação dessa eternidade e, paradoxalmente, uma representação do infinito numa região espacial limitada e num intervalo de tempo limitado.

No entanto, na análise da geometria fractal podemos também proceder de modo inverso: partir de uma representação visual e tentar encontrar a sua equação fractal, isto é, algo que contenha um número reduzido de informação, mas permita reproduzir a complexidade. Procedemos deste modo a uma compressão de representações visuais. Este aspecto não é metafórico, pois na realidade muitas representações em CD-ROM utilizam já compressão fractal. Este percurso - de uma imagem ou de um comportamento que pretendemos explicar a um algoritmo fractal comprimido que codifica tal imagem ou comportamento - parece encerrar múltiplas potencialidades. Os sistemas auto-organizados têm propriedades emergentes que são propriedades do sistema como um todo, mas não de cada um dos elementos de que o sistema é composto. Surge então a questão de saber se não poderá existir alguma analogia entre a compressão fractal e a codificação biológica da informação. Será lícito pensar acerca da vida, do ADN, como contendo algo como uma descrição fractal comprimida? Isto é, as propriedades emergentes poderão ser perspectivadas de modo análogo a uma equação fractal? Ou, de modo menos matemático, a complexidade pode sempre ser gerada por uma pequena quantidade de informação?

Analisemos agora a geometria fractal de um ponto de vista emocional. Ela produz objectos fascinantes e estranhos. Será que os poderemos considerar manifestações artísticas? Sem pretendermos propor uma (impossível) definição abrangente de arte, sublinharíamos que a arte:

- resulta de um trabalho intelectual;

- produz emoções;

- contém novos elementos visuais e intelectuais;

- e representa uma visão pessoal e intencional de um certo universo.

Apresentarão as imagens fractais tais características? Há, naturalmente, diferentes respostas a esta pergunta.

$\mathrm{O}$ investigador no domínio do caos ou da geometria fractal produz de certo modo um objecto de arte, pois podemos encontrar nos seus fractais 
trabalho intelectual, emoções, novos elementos visuais e intelectuais e uma interpretação complexa de uma certa fracção do universo. Uma segunda resposta diz respeito a todos os que são de algum modo inspirados pela geometria fractal ${ }^{1}$, não sendo obviamente a simples referência à geometria fractal suficiente para garantir qualidade artística. Por fim, a terceira resposta toca o utilizador de programas de geometria fractal. Quando este se senta em frente do seu computador e itera uma função complexa não produz arte. Presta, talvez, homenagem a Benoît Mandelbrot.

Os grandes avanços nas visões do universo estiveram desde sempre ligados a esses descobridores de mundos representados pelos instrumentos que progressivamente estenderam os territórios conhecidos:

- os territórios do infinitamente pequeno descobertos pelo microscópio;

- os territórios do infinitamente grande descobertos pelo telescópios e pelo radiotelescópio;

- os territórios dos procedimentos infinitamente complexos, conquistados pelo computador.

Mas é com a geometria fractal que estes últimos territórios podem assumir uma nova dimensão. Os fractais representam, por excelência, a síntese num único objecto das escalas infinitamente pequenas, como também das escalas infinitamente grandes. E é assim, justamente, que os computadores, esses descobridores de complexidade - que se suspeitava imprimirem uma ordem e uma disciplina absoluta à vida humana tornam possível a compreensão da harmonia e do caos, desvendando paraísos sensoriais na aparente frieza que caracteriza as ciências exactas. Através da geometria fractal e de instrumentos computacionais, sublinha-se assim, de modo amplamente compreensível, que existe uma ligação palpável entre uma abordagem científica do real e uma abordagem estética, ligação esta que confere uma nova dimensão aos aspectos estéticos que os investigadores associam geralmente ao seu trabalho científico. Caracterizada por uma harmoniosa interacção de imprevisibilidade e ordem, surge esta nova dimensão, que desvenda uma surpreendente luxúria científica.

${ }^{1}$ Como por exemplo o grupo francês Itinéraire fractal. 
(Página deixada propositadamente em branco) 
 \\ A palavra "fronteiras" pode ser tomada em} diferentes sentidos. Pode referir-se aos limites, necessariamente provisórios, entre o conhecido e o desconhecido, ou aos limites entre o possivel e o impossivel, e, dentro do possivel, entre o desejável e 0 indesejável. Fronteiras podem também ser as delimitações, nem sempre nítidas, entre ciência e não-ciência, e dentro da ciência, entre as várias disciplinas. Quais são então as fronteiras da ciência?

Neste livro, a resposta a esta pergunta é dada, segundo as mais diferentes perspectivas, por um conjunto notável de personalidades, cientistas ou não, entre as quais se contam três Prémios Nobel.

Rui Fausto, Carlos fiolhais e JoÃo Fillipe Queiró são, respectivamente, professores de Química, Física e Matemática na Faculdade de Ciências e Tecnologia da Universidade de Coimbra. 